\title{
SOS1, a Genetic Locus Essential for Salt Tolerance and Potassium Acquisition
}

\author{
Shaw-Jye Wu, Lei Ding, ${ }^{1}$ and Jian-Kang Zhu ${ }^{1,2}$ \\ Department of Botany and Microbiology, Auburn University, Auburn, Alabama 36849
}

\begin{abstract}
To begin to determine which genes are essential for salt tolerance in higher plants, we identified four salt-hypersensitive mutants of Arabidopsis by using a root-bending assay on $\mathrm{NaCl}$-containing agar plates. These mutants (sos1-1, sos1-2, sos1-3, and sos1-4) are allelic to each other and were caused by single recessive nuclear mutations. The SOS1 gene was mapped to chromosome 2 at $29.5 \pm 6.1$ centimorgans. The mutants showed no phenotypic changes except that their growth was $>\mathbf{2 0}$ times more sensitive to inhibition by $\mathbf{N a C l}$. Salt hypersensitivity is a basic cellular trait exhibited by the mutants at all developmental stages. The sos1 mutants are specifically hypersensitive to $\mathrm{Na}^{+}$and $\mathrm{Li}^{+}$. $\mathrm{The}^{\mathrm{mu}-}$ tants were unable to grow on media containing low levels (below $\sim 1 \mathrm{mM}$ ) of potassium. Uptake experiments using ${ }^{86} \mathrm{Rb}$ showed that sos1 mutants are defective in high-affinity potassium uptake. sos1 plants became deficient in potassium when treated with $\mathrm{NaCl}$. The results demonstrate that potassium acquisition is a critical process for salt tolerance in glycophytic plants.
\end{abstract}

\section{INTRODUCTION}

Plants experience constant fluctuations in the availability and quality of soil water. The quality of soil water is influenced mostly by the concentrations of essential plant mineral nutrients as well as nonessential ions. Nonessential ions, such as $\mathrm{Na}^{+}$, when present in high concentrations in the soil, adversely affect plant growth (Greenway and Munns, 1980). Excessive $\mathrm{Na}^{+}$in the soil, often referred to as salinity, is a major problem for a substantial portion of agricultural land in the world (Epstein et al., 1980). Recently, much effort has been directed toward understanding the molecular and cellular mechanisms by which plants tolerate salinity stress, with the eventual goal of improving salt tolerance of crop plants (Binzel and Reuveni, 1994). One important objective is to determine which genes are important for plant salt tolerance. A widely used approach has been to identify genes whose expression is regulated by salt stress. Many salt-regulated genes have been identified in the last decade. Identification of these genes has permitted a better understanding of the complexity of salt tolerance in higher plants (Cushman et al., 1990; Bray, 1993; Serrano and Gaxiola, 1994). However, the function of most of the gene products in salt tolerance has been difficult to establish (Bray, 1993; Serrano and Gaxiola, 1994). This approach is also unsuitable for identifying low-abundance mRNAs and proteins that might have important regulatory roles in salt responses. Clearly, a genetic approach is needed to determine which genes are necessary for salt tolerance.

\footnotetext{
${ }^{1}$ Current address: Department of Plant Sciences, University of Arizona, Tucson, AZ 85721.

${ }^{2}$ To whom correspondence should be addressed.
}

Potassium is a major monovalent cationic essential nutrient. Potassium uptake plays a vital role in plant growth, development, stomatal movements, enzyme activation, and osmoregulation (Epstein, 1972; Kochian and Lucas, 1988). It is generally accepted that potassium uptake into plant cells is mediated by two mechanisms operating on the plasma membrane (Epstein, 1966). One is a low-affinity system that functions only when extracellular potassium concentration is high (millimolar range). The second is a high-affinity system that functions at low extracellular potassium concentrations (micromolar range). Physiological studies indicate that high levels of $\mathrm{Na}^{+}$inhibit $\mathrm{K}^{+}$uptake through the low-affinity system (Rains and Epstein, 1967). Recently, several $\mathrm{K}^{+}$channel homologs have been identified from Arabidopsis by com. plementation of $\mathrm{K}^{+}$uptake-deficient yeast mutants ( $\mathrm{Ko}$ and Gaber, 1991) and patch clamp analysis with Xenopus (Anderson et al., 1992; Schachtman et al., 1992; Sentanec et al., 1992; Schroeder et al., 1994; Hadjeb and Berkowitz, 1995). Some of the inward-rectifying $\mathrm{K}^{+}$channels probably serve as the lowaffinity $\mathrm{K}^{+}$uptake system (Schroeder et al., 1994). Using a similar approach of yeast complementation, Schachtman and Schroeder (1994) have cloned a high-affinity $\mathrm{K}^{+}$transporter from wheat that could be part of the high-affinity $\mathrm{K}^{+}$uptake system in higher plants. The functions of the cloned $\mathrm{K}^{+}$channels and transporters in $\mathrm{K}^{+}$acquisition and salt tolerance in plants, however, remain to be determined.

We have used a molecular genetic approach with Arabidopsis as a model system to understand salt tolerance mechanisms in glycophytic plants. We reasoned that genes essential for salt tolerance could be identified by selecting and characteriz- 

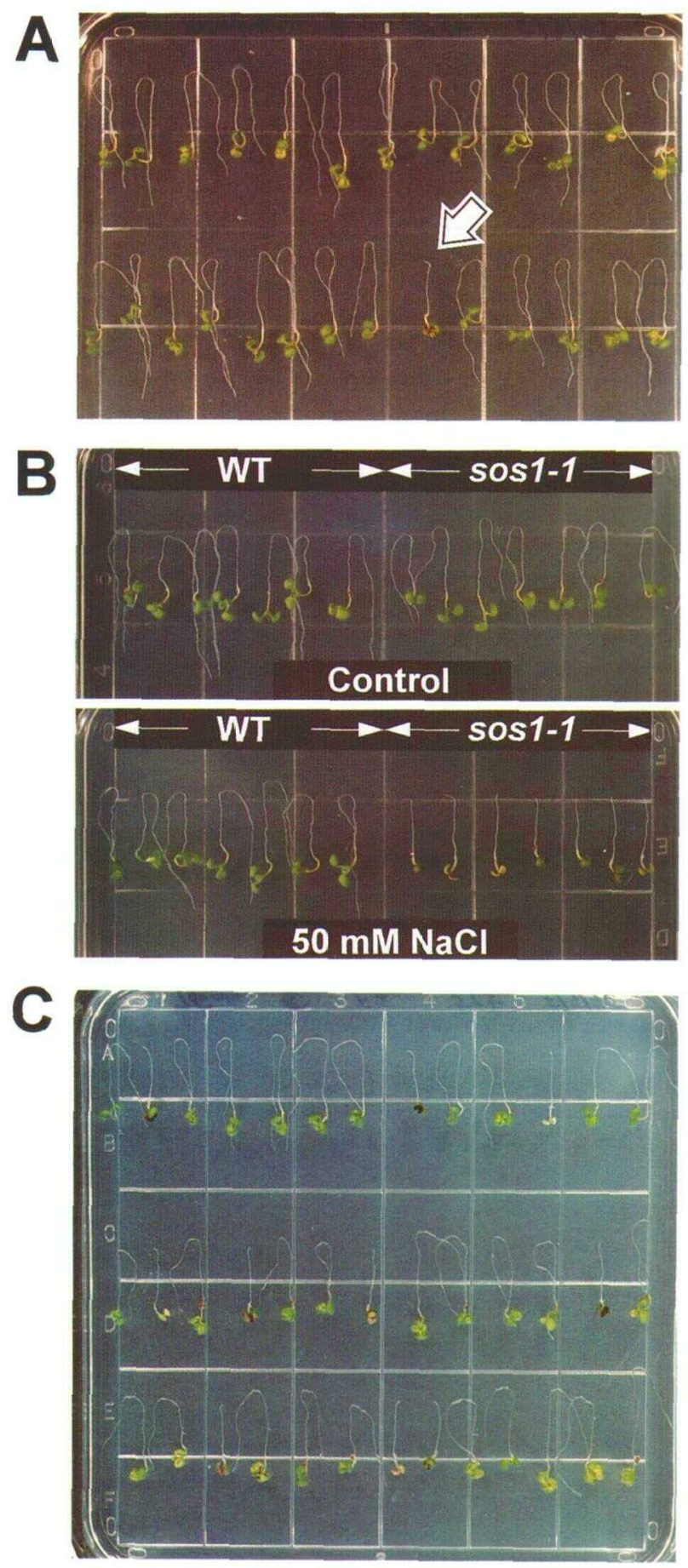

Figure 1. Use of the Root-Bending Assay for Selection and Characterization of Salt-Hypersensitive Mutants.

Four-day-old Arabidopsis seedlings with 1- to 1.5-cm-long roots, on vertical agar plates, were transferred to plates supplemented with $\mathrm{NaCl}$ and allowed to grow upside down.

(A) Seedlings from EMS-mutagenized $M_{2}$ seeds were screened on $50 \mathrm{mM} \mathrm{NaCl}$ plates for sos mutants. The arrow points to a putative sos mutant. ing salt-hypersensitive mutants. In this study, we isolated and characterized four Arabidopsis mutants whose growth is hypersensitive to $\mathrm{NaCl}$ inhibition. These mutants define one genetic locus that is essential for salt tolerance. We show that this locus is also required for high-affinity $\mathrm{K}^{+}$uptake.

\section{RESULTS}

\section{Isolation of Salt-Hypersensitive Mutants}

$\mathrm{NaCl}$ stress inhibits plant root and shoot growth. Arabidopsis is a glycophytic species that is sensitive to low to moderate levels of $\mathrm{NaCl}$ stress. The growth inhibition by $\mathrm{NaCl}$ of Arabidopsis seedlings can be conveniently observed as a reduction in root elongation as well as cotyledon and leaf expansion. We characterized the inhibition of seedling root elongation by using a root-bending assay modified from Howden and Cobbett (1992). In this assay, young seedlings growing uniformly in the absence of salt stress are transferred and placed with roots upside down onto vertical agar plates containing appropriate levels of $\mathrm{NaCl}$ as the stress agent. Continued growth on the salt plates results in bending of the roots due to gravitropism; thus, lack of root bending is a visual sign of growth inhibition by $\mathrm{NaCl}$ (Figures $1 \mathrm{~A}$ to $1 \mathrm{C}$ ). Agravitropic mutants can be easily distinguished from true salt-hypersensitive mutants because the former can exhibit continued upward root growth and uninhibited shoot growth. Murphy and Taiz (1995) have developed a vertical-mesh-transfer technique for rapid screening of heavy metal tolerance mutants that is related to this screening method. This new technique may also be useful for faster screening of $\mathrm{NaCl}$-hypersensitive mutants in the future.

We screened $\sim 50,000$ ethylmethane sulfonate (EMS)mutagenized $\mathrm{M}_{2}$ seeds for $\mathrm{NaCl}$-hypersensitive mutants, using the root-bending assay on $50 \mathrm{mM} \mathrm{NaCl}$ plates (Figure 1A). This amount $(50 \mathrm{mM})$ of $\mathrm{NaCl}$ has no obvious effect on the root bending of wild-type (Columbia ecotype) seedlings (Figure 1) that could exhibit uniform root bending on plates containing up to $150 \mathrm{mM} \mathrm{NaCl}$ (data not shown). Of 21 putative mutants obtained, four remained hypersensitive to $\mathrm{NaCl}$ stress in the $M_{3}$ generation and were named salt overly sen-

(B) Rescreening of putative sos mutants, using the root-bending assay. sos1-1 seedlings shown here exhibited normal root bending on medium without $\mathrm{NaCl}$ (Control) but no root bending on medium supplemented with $50 \mathrm{mM} \mathrm{NaCl}(50 \mathrm{mM} \mathrm{NaCl})$, thus demonstrating that it is a true salt-hypersensitive mutant. WT, wild type.

(C) $F_{2}$ segregation analysis, using the root-bending assay. Uniformly grown $F_{2}$ seedlings from a cross between the wild type and sos $1-1$ were transferred onto medium supplemented with $75 \mathrm{mM} \mathrm{NaCl}$. The wild type (with root bending)-to-sos1-1 (without root bending) ratio is $\sim 3: 1$, indicating that sos $1-1$ is caused by a single recessive nuclear mutation. 


\begin{tabular}{|c|c|c|c|c|c|}
\hline Strains or Crosses $(Q \times \phi)$ & Generation & Total Seedlings Tested & Resistant $^{\mathrm{a}}$ & Sensitive & $\chi^{2}$ \\
\hline Wild-type Columbia & & 4982 & 4982 & 0 & \\
\hline $\operatorname{sos} 1-1 / \operatorname{sos} 1-1$ & & 1473 & 0 & 1473 & \\
\hline $\operatorname{sos} 1-2 / \operatorname{sos} 1-2$ & & 435 & 0 & 435 & \\
\hline $\operatorname{sos} 1-3 / \operatorname{sos} 1-3$ & & 423 & 0 & 423 & \\
\hline $\operatorname{sos} 1-4 / \operatorname{sos} 1-4$ & & 379 & 0 & 379 & \\
\hline \multirow[t]{2}{*}{ Wild type $\times$ sos $1-1 / \operatorname{sos} 1-1$} & $F_{1}$ & 54 & 54 & 0 & \\
\hline & $\mathrm{F}_{2}$ & 231 & 175 & 56 & $0.071^{b}$ \\
\hline sos $1-2 / \operatorname{sos} 1-2 \times$ wild type & $F_{1}$ & 59 & 59 & 0 & \\
\hline sos $1-3 / \operatorname{sos} 1-3 \times$ wild type & $F_{1}$ & 34 & 37 & 0 & \\
\hline sos $1-4 /$ sos $1-4 \times$ wild type & $F_{1}$ & 37 & 37 & 0 & \\
\hline $\operatorname{sos} 1-2 / \operatorname{sos} 1-2 \times \operatorname{sos} 1-1 / \operatorname{sos} 1-1$ & $F_{1}$ & 30 & 0 & 30 & \\
\hline $\operatorname{sos} 1-1 / \operatorname{sos} 1-1 \times \operatorname{sos} 1-3 / \operatorname{sos} 1-3$ & $F_{1}$ & 35 & 0 & 35 & \\
\hline $\operatorname{sos} 1-1 / \operatorname{sos} 1-1 \times \operatorname{sos} 1-4 / \operatorname{sos} 1-4$ & $F_{1}$ & 46 & 0 & 46 & \\
\hline $\operatorname{sos} 1-2 / \operatorname{sos} 1-2 \times \operatorname{sos} 1-3 / \operatorname{sos} 1-3$ & $F_{1}$ & 16 & 0 & 16 & \\
\hline
\end{tabular}

a Resistant or sensitive was determined in the root-bending assay, using $75 \mathrm{mM} \mathrm{NaCl}$.

b The calculated value was based on the expected ratio of three wild-type (i.e., resistant) seedlings to one mutant (i.e., sensitive) seedling; $P>$ 0.05 .

sitive (sos) mutants. Figure $1 \mathrm{~B}$ shows the test of $\mathrm{M}_{3}$ seedlings of sos1-1. With or without salt stress, the phenotypes of the other three independent mutants are identical to sos1-1.

\section{Genetic Characterization of sos1}

Genetic analysis showed that all four mutations are recessive and are allelic to each other (Table 1). The analysis of the selfed $F_{2}$ seedlings from a cross between sos1-1 and the wild type revealed a 3:1 segregation ratio of wild type/sos1-1 (Table 1). Therefore, the sos1 mutants are caused by single recessive nuclear mutations. An example of the segregation analysis from the root-bending assay is shown in Figure 1C. Unless specified otherwise, all subsequent characterizations were performed with sos1-1.

\section{Salt Hypersensitivity of sos1 Mutants Is a Basic Cellular Trait and is Expressed at All Developmental Stages}

The salt sensitivity of the sos 1 mutant was quantified by measuring root elongation of seedlings placed on agar plates containing different levels of $\mathrm{NaCl}$. Root elongation is a convenient and accurate indicator of plant growth because we found that root and shoot growth of the Arabidopsis lines presented in this study are always simultaneously inhibited by $\mathrm{NaCl}$. The concentration of $\mathrm{NaCl}$ that decreased the root elongation rate by $50 \%$ relative to medium without salt $\left(I_{50}\right)$ was estimated. The $I_{50}$ concentrations for sos 1 and the wild type are $\sim 4$ and $96 \mathrm{mM}$, respectively (Figure 2). Thus, sos1 seedlings are $>20$ times more sensitive to $\mathrm{NaCl}$ than are the wild-type seedlings.
Salt sensitivity of plants often depends on developmental stages. We determined whether sos 1 is also hypersensitive to $\mathrm{NaCl}$ at developmental stages other than the seedling. Germination of sos1 seed was found to be hypersensitive to $\mathrm{NaCl}$

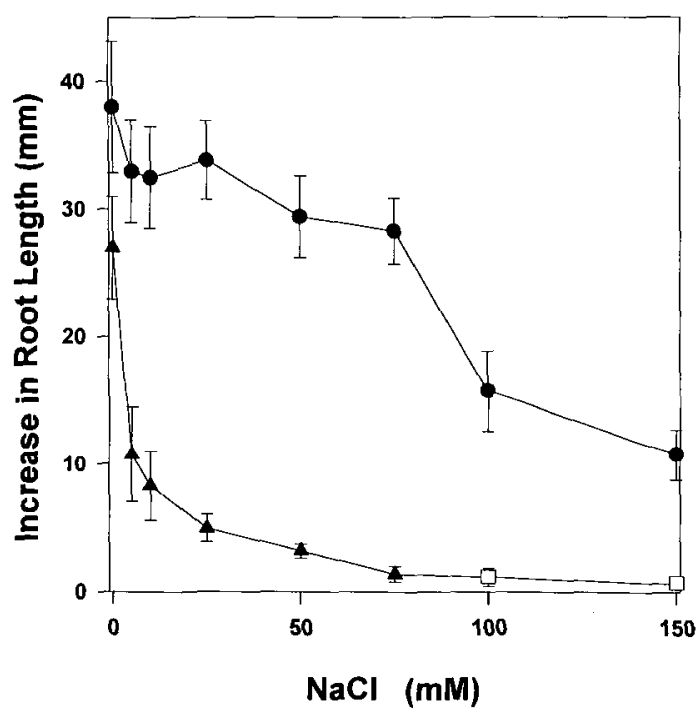

Figure 2. sos 1 Seedlings Are $>20$ Times More Sensitive to $\mathrm{NaCl}$ Than Are Wild-Type Seedlings.

Root elongation of sos1 and wild-type seedlings was measured to quantify their sensitivities toward $\mathrm{NaCl}$ inhibition. Estimated $/ 50$ con centrations ( $\mathrm{NaCl}$ concentration at $50 \%$ inhibition) are 4 and $96 \mathrm{mM}$ for sos1 and the wild type, respectively. Shown are root elongation data 7 days after transfer to $\mathrm{NaCl}$ plates. Root elongation data were also obtained on days 1 to 6 , and they yielded similar $I_{50}$ concentrations. -, wild type; $\wedge$, sos1; $\square$, dead sos1. 
inhibition (data not shown). At $100 \mathrm{mM} \mathrm{NaCl}$, the germination rate of the wild type was not affected, whereas sos1 was inhibited to $\sim 35 \%$. The wild-type seeds that could not germinate on $200 \mathrm{mM} \mathrm{NaCl}$ all were able to germinate after being transferred to media without $\mathrm{NaCl}$. However, none of the sos1 seeds that did not germinate on $\mathrm{NaCl}$-containing media was able to germinate on media without $\mathrm{NaCl}$, indicating that these mutant seeds had been permanently damaged by $\mathrm{NaCl}$.

Rosette leaves of sos 1 and wild-type plants also were examined for $\mathrm{NaCl}$ responses. The growth of sos1 plants was completely inhibited by watering with a solution containing 25 $\mathrm{mM} \mathrm{NaCl}$, whereas the wild type could grow in the presence of $100 \mathrm{mM} \mathrm{NaCl}$ (Figure 3).

To determine whether the $\mathrm{NaCl}$ hypersensitivity of sos1 is a basic cellular trait or associated with only specific cell and tissue types of intact plants, calli were generated from mutant and wild-type seeds. In the absence of $\mathrm{NaCl}$, growth of sos1 calli was not different from that of the wild type. sos 1 calli could not grow on media containing $100 \mathrm{mM} \mathrm{NaCl}$ and were killed by $150 \mathrm{mM} \mathrm{NaCl}$ (Figure 4). In contrast, the wild-type calli could grow on $100 \mathrm{mM} \mathrm{NaCl}$ (Figure 4) and survive on $150 \mathrm{mM} \mathrm{NaCl}$ (data not shown). The results show that the $\mathrm{NaCl}$ hypersensitivity of sos1 is a basic cellular trait and that it is expressed at all developmental stages and in cultured cells of the mutant. sos1 Is Specifically Hypersensitive to $\mathrm{Na}^{+}$and $\mathrm{Li}^{+}$

Because the salt that we used is $\mathrm{NaCl}$, we wanted to determine whether sos1 is hypersensitive to $\mathrm{Na}^{+}$or $\mathrm{Cl}^{-}$or both. As shown in Figure $5 \mathrm{~A}$, sos1 is hypersensitive to $\mathrm{NaCl}$ but not to $\mathrm{KCl}$. Furthermore, sos1 is hypersensitive to $\mathrm{Na}_{2} \mathrm{SO}_{4}$ but not to $\mathrm{K}_{2} \mathrm{SO}_{4}$ (Figure 5B). Therefore, sos1 is hypersensitive to $\mathrm{Na}^{+}$ but not to $\mathrm{Cl}^{-}, \mathrm{SO}_{4}{ }^{2-}$, or $\mathrm{K}^{+}$. In addition to $\mathrm{Na}^{+}$, sos1 is also hypersensitive to $\mathrm{Li}^{+}$(Figure 6A). $\mathrm{Li}^{+}$is generally considered a more toxic analog for $\mathrm{Na}^{+}$(Mendoza et al., 1994). Ten millimolars $\mathrm{LiCl}$ did not inhibit the wild type; however, it exerted $>80 \%$ inhibition on sos1 plants. Interestingly, sos1 is not hypersensitive to $\mathrm{Cs}^{+}$(Figure 6B), another very toxic monovalent cation (Sheahan et al., 1993).

\section{sos1 Cannot Grow on Low-Potassium Media}

As part of our effort to characterize the responses of sos1 to various salts, we tested sos1 seedlings on media containing various levels of $\mathrm{KCl}$. Regular Murashige and Skoog (MS) medium (Murashige and Skoog, 1962) contains $\sim 20 \mathrm{mM} \mathrm{K}^{+}$. sos1 grew well with this level of $\mathrm{K}^{+}$(Figure 1). Adding additional $\mathrm{KCl}$ to $\mathrm{MS}$ media reduced the growth of both sos1 and

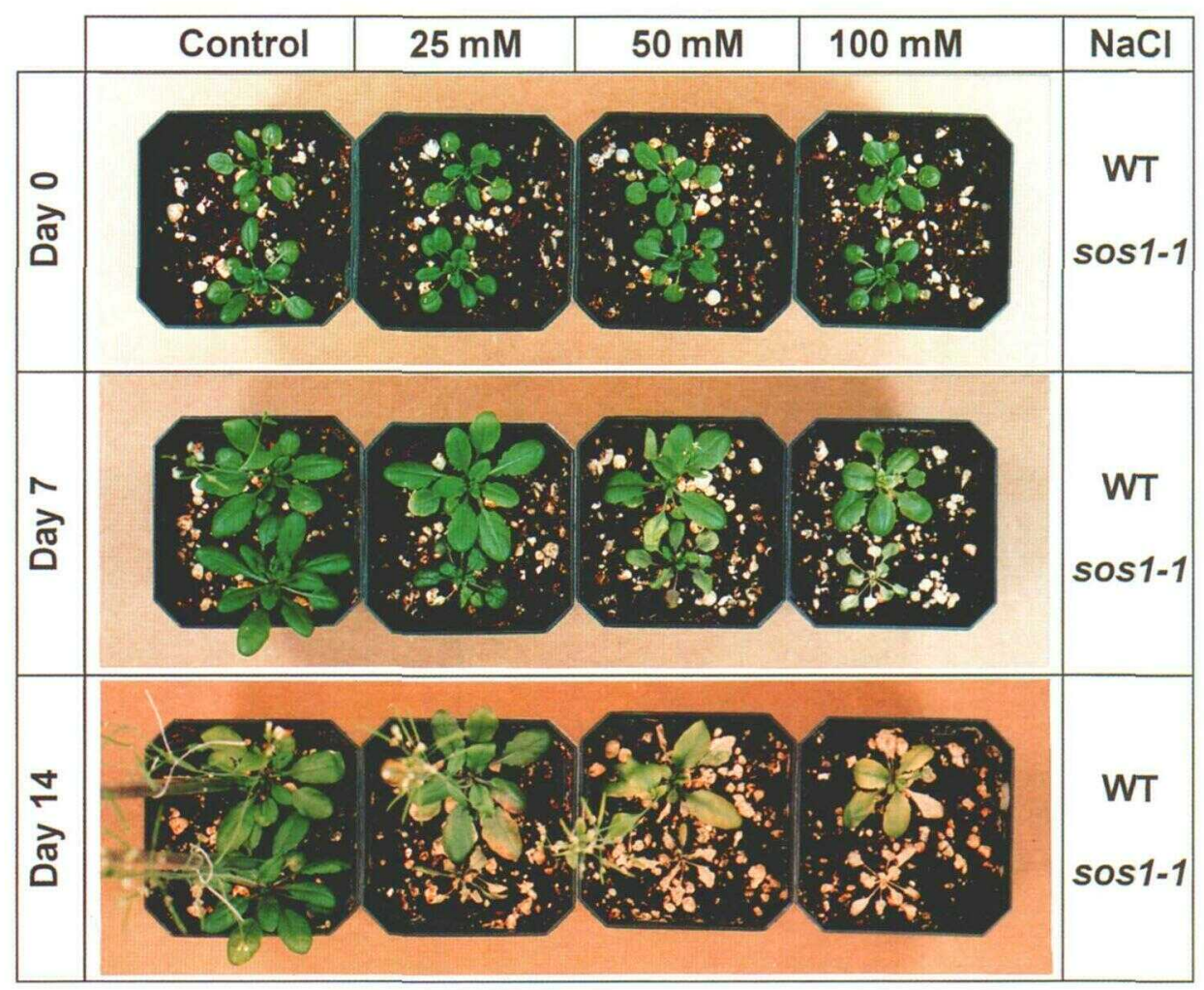

Figure 3. Soil-Grown sos1 Plants Are Hypersensitive to $\mathrm{NaCl}$.

Plants with eight to 10 rosette leaves were flooded every 3 days with either distilled water (Control) or 25,50 , or $100 \mathrm{mM} \mathrm{NaCl}$ solution. WT, wild type. 


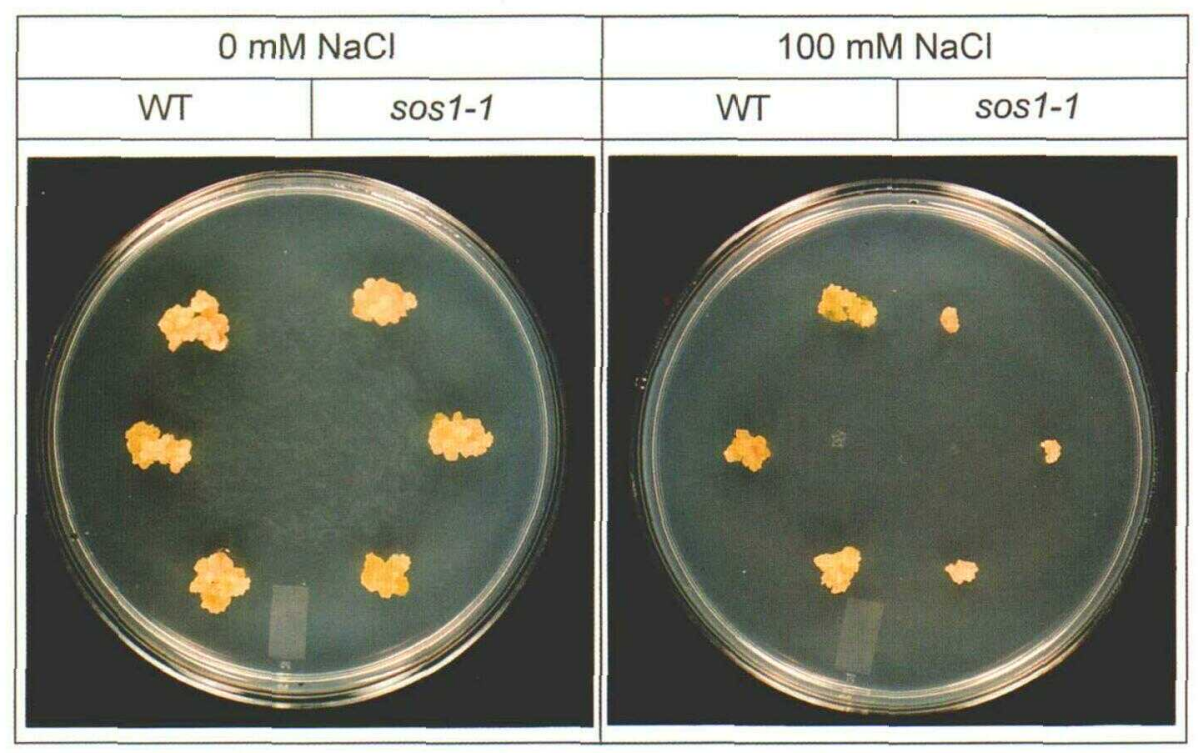

Figure 4. Callus Tissue Derived from sos 1 Is Hypersensitive to $\mathrm{NaCl}$.

The calli were photographed 10 days after treatment. sos 1 calli did not grow at all on $100 \mathrm{mM} \mathrm{NaCl}$ medium and were killed within 1 week after being transferred to the $\mathrm{NaCl}$ medium. WT, wild type.

the wild type, presumably due to osmotic stress (data not shown). However, when the $\mathrm{K}^{+}$levels in the MS medium were reduced to $200 \mu \mathrm{M}$, sos1 could not grow, whereas the wild type grew relatively well (Figure 7). Replacing $\mathrm{NH}_{4} \mathrm{NO}_{3}$ in the lowpotassium medium with Tris-nitrate did not improve the growth of sos1 or the wild type, indicating that the lack of growth of sos1 on the $200 \mu \mathrm{M} \mathrm{K}^{+}$medium was not due to inhibition by $\mathrm{NH}_{4}{ }^{+}$(data not shown). Quantitative measurement of root elongation indicated that sos1 could not grow on media containing $<1 \mathrm{mM} \mathrm{K}^{+}$, whereas the growth of the wild type was not affected by $\mathrm{K}^{+}$levels (Figure 8 ). It should be noted that the agar medium could sustain the growth of wild-type seedlings even without any added $\mathrm{K}^{+}$, presumably because of a low level of $\mathrm{K}^{+}$contamination in the agar (Sheahan et al., 1993).

\section{sos1 Is Deficient in High-Affinity $\mathrm{K}^{+}$Uptake}

The observation that sos1 needs high levels of $\mathrm{K}^{+}$to grow indicates that the mutant may be deficient in high-affinity $\mathrm{K}^{+}$ uptake. The capacity for $\mathrm{K}^{+}$absorption was determined by measuring ${ }^{86} \mathrm{Rb}^{+}$uptake into sos 1 and the wild-type seedlings. The uptake rate for $\mathrm{K}^{+}$was at least twofold lower in sos1 than in the wild type when the external $\mathrm{K}^{+}$concentration was $200 \mu \mathrm{M}$. However, there was no difference in $\mathrm{K}^{+}$uptake rate between sos 1 and the wild type when the external $\mathrm{K}^{+}$was 20 $\mathrm{mM}$ (Figure 9). These uptake results are very consistent with the growth data in Figure 8 and demonstrate that sos 1 is indeed defective in the high-affinity $\mathrm{K}^{+}$uptake system and that it contains a normal low-affinity $\mathrm{K}^{+}$uptake system.
$\mathrm{K}^{+}$uptake rates as a function of $\mathrm{K}^{+}$concentration in the external media were determined for both sos 1 and the wild type at the high-affinity range. The uptake in sos1 was consistently lower than in the wild type (Figure 10A). Assuming that sos1 is defective in a high-affinity $\mathrm{K}^{+}$transport system, then the difference between the uptake rates in the wild type and sos 1 may correspond to the uptake mediated through this highaffinity system. A plot of the difference in uptake rates, as a function of potassium concentration, approximates a saturable system (Figure 10B). The $K_{\mathrm{m}}$ and $V_{\max }$ concentrations for this system were estimated to be $256 \mu \mathrm{M}$ and $796 \mathrm{nmol} / \mathrm{hr} / \mathrm{g}$ fresh weight, respectively, based on the Hanes plot (Figure $10 \mathrm{~B})$. The estimated $K_{m}$ value is lower than $420 \mu \mathrm{M}$ as determined by Polley and Hopkins (1979) but higher than $30 \mu \mathrm{M}$ obtained by Maathuis and Sanders (1994). The discrepancies could be caused by different methodologies as well as the status of the plants used.

\section{Potassium Deficiency in $\mathrm{NaCl}-\mathrm{Stressed}$ sos1}

$\mathrm{K}^{+}$content in $\mathrm{NaCl}$-treated sos1 seedlings was measured to determine whether the mutant was deficient in $\mathrm{K}^{+}$. After 24 $\mathrm{hr}$ of exposure to various levels of $\mathrm{NaCl}$, the $\mathrm{K}^{+}$content was decreased in both sos1 and the wild-type plants (Figure 11). More importantly, this decrease was greater in sos1 at all $\mathrm{NaCl}$ concentrations (Figure 11). The $\mathrm{K}^{+}$content in the wild type did not decrease to $<3 \%$ of the dry weight, whereas in sos 1 it decreased to $\sim 1 \%$. The results demonstrate that $\mathrm{K}^{+}$deficiency occurs in $\mathrm{NaCl}$-treated sos1 plants. 
A

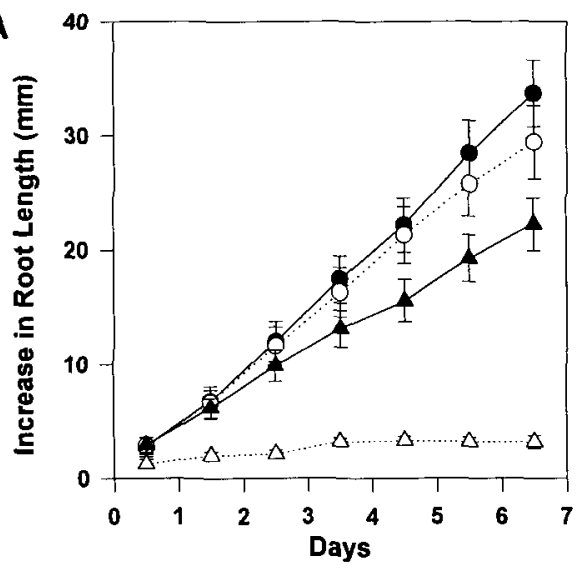

B

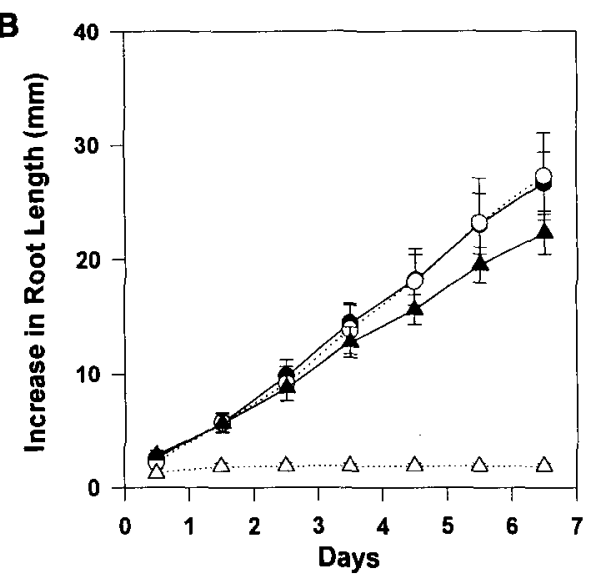

Figure 5. Growth Response of sos1 and Wild-Type Seedlings toward $\mathrm{NaCl}, \mathrm{KCl}, \mathrm{Na}_{2} \mathrm{SO}_{4}$, and $\mathrm{K}_{2} \mathrm{SO}_{4}$.

sos1 is hypersensitive to $\mathrm{Na}^{+}$but not to $\mathrm{Cl}^{-}, \mathrm{SO}_{4}{ }^{2-}$, or $\mathrm{K}^{+}$.

(A) Growth response toward $\mathrm{NaCl}$ and $\mathrm{KCl}$. , wild type on $50 \mathrm{mM}$ $\mathrm{KCl}$; , wild type on $50 \mathrm{mM} \mathrm{NaCl}$; , sos1 on $50 \mathrm{mM} \mathrm{KCl}, \triangle$, sos1 on $50 \mathrm{mM} \mathrm{NaCl}$.

(B) Growth response toward $\mathrm{Na}_{2} \mathrm{SO}_{4}$ and $\mathrm{K}_{2} \mathrm{SO}_{4}$. , wild type on 25 $\mathrm{mM} \mathrm{K}_{2} \mathrm{SO}_{4} ; \mathrm{O}$, wild type on $25 \mathrm{mM} \mathrm{Na}_{2} \mathrm{SO}_{4} ; \Delta$, sos1 on $25 \mathrm{mM}$ $\mathrm{K}_{2} \mathrm{SO}_{4} ; \triangle$, sos1 on $25 \mathrm{mM} \mathrm{Na}_{2} \mathrm{SO}_{4}$.

\section{Map Position of sos1}

As a first step toward cloning SOS1, the chromosomal map position of sos1 was determined by using a combination of the visible glabrous $(g / 1)$ marker (Koornneef et al., 1982), microsatellite markers (Bell and Ecker, 1994), and cleaved amplified polymorphic sequence (CAPS) markers (Konieczny and Ausubel, 1993). Homozygous sost-1 plants in the Columbia g/1 background were crossed to plants of the Landsberg erecta background. The resulting $F_{2}$ population segregated for the sos1 and g/1 phenotypes and for Landsberg erecta and Columbia microsatellite and CAPS markers. In 43 of the sos 1 mutants recovered, 36 were found to be $G L 1$, indicating that $\operatorname{sos} 1$ is not linked to this gil locus on chromosome 3. DNA was iso- lated from sos 1 homozygotes from the $F_{2}$ population, and segregation of microsatellite markers was determined. sos1 showed linkage to nga168 on chromosome 2 (Table 2) and no linkage to nga63 and nga111 on chromosome 1 , nga8 on chromosome 4 , or $n$ ga 225 and $n g a 76$ on chromosome 5 . Segregation of the CAPS marker GPA1 on chromosome 2 was then determined. As shown in Table 2, sos 1 is more closely linked to GPA1. By using the Kosambi function (Koorneef and Stam, 1992), the map position of sos 1 was calculated to be $29.5 \pm$ 6.1 centimorgans on the upper arm of chromosome 2.

\section{DISCUSSION}

In this study, we report the isolation and characterization of salt-hypersensitive mutants of Arabidopsis. The fact that the
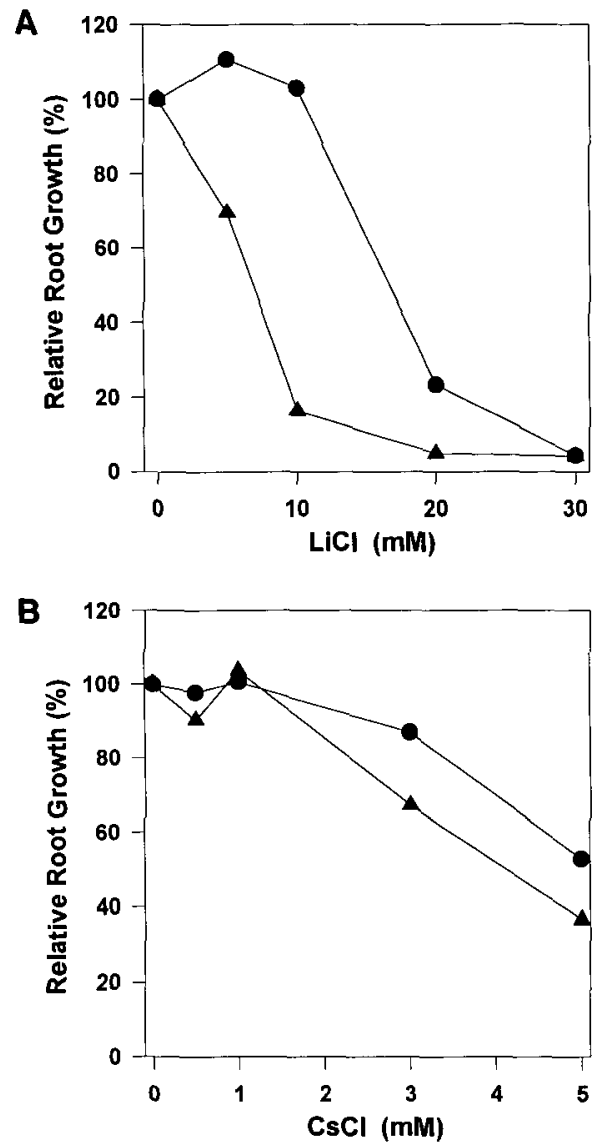

Figure 6. sos1 Seedlings Are Hypersensitive to $\mathrm{Li}^{+}$but Not $\mathrm{Cs}^{+}$.

Relative root growth was calculated as the percentage of growth in the presence of salt (i.e., $\mathrm{Li}^{+}$or $\mathrm{Cs}^{+}$) over growth in the absence of salt.

(A) Relative growth on $\mathrm{LiCl}$.

(B) Relative growth on $\mathrm{CsCl}$.

- wild type; $\boldsymbol{\Lambda}$, sos1. 

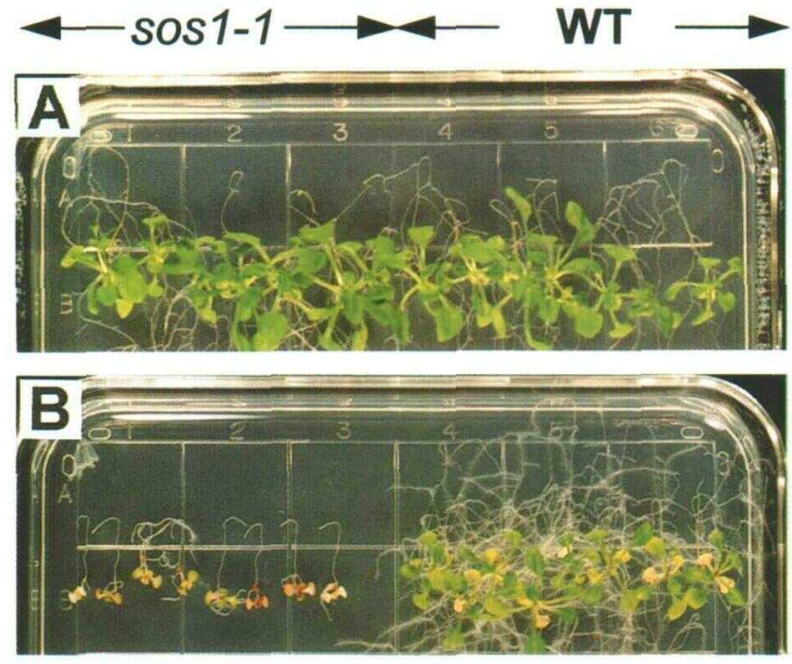

Figure 7. sos1 Plants Cannot Grow with Low Levels of Potassium.

Four-day-old sos1 and wild-type seedlings grown on MS medium were transferred to media containing various levels of $\mathrm{K}^{+}$.

(A) Plants on $20 \mathrm{mM} \mathrm{K}^{+}$.

(B) Plants on $200 \mu \mathrm{M} \mathrm{K}^{+}$.

The plants were photographed 2 weeks after the transfer. WT, wild type.

mutants appear normal on regular growth media suggests that the affected locus is not essential for normal plant growth and development but is required for salt tolerance. Furthermore, we found that the underlying reason for the salt hypersensitivity is a defective high-affinity potassium uptake system. These mutants will serve as an invaluable tool for understanding salt tolerance mechanisms as well as the role of potassium and its high-affinity uptake in various physiological processes in plants.

\section{Molecular Genetic Approach to Studying Salt Tolerance}

Arabidopsis has proven to be a very powerful model system for developmental and hormonal research on higher plants (Meyerowitz and Sormerville, 1994). It also has been used successfully to analyze plant interactions with biotic as well as certain abiotic factors. However, its use in studies on plant salt responses has been very limited. Werner and Finkelstein (1995) as well as Saleki et al. (1993) have selected several Arabidopsis mutants that can germinate in the presence of high salt. However, these mutants were not more salt tolerant beyond the germination stage. An alternative approach to understanding salt tolerance is to select for mutants that have lost certain salt tolerance mechanisms and are thus more sensitive to salt stress than is the wild type. In practice, the application of this straightforward strategy has been hampered in part by the fact that wild-type Arabidopsis is very sensitive to $\mathrm{NaCl}$. Nevertheless, we demonstrated in this study that it is possible to isolate mutants that are hypersensitive to $\mathrm{NaCl}$ and that the mutants are extremely useful for the identification of genes essential for salt tolerance. The mutants presented here define a gene (i.e., SOS1) involved in potassium acquisition. We have since isolated more $\mathrm{NaCl}$-hypersensitive mutants (L. Ding and J.-K. Zhu, unpublished data). These mutants may define genes involved in other plant processes that are important in salt tolerance, such as $\mathrm{Na}^{+}$extrusion and compartmentation, the synthesis of compatible osmolytes, ionic and osmotic sensing and signal transduction, or even in some as yet unknown processes required for salt tolerance. Salt-sensitive yeast mutants defective in one of many of these processes have been identified recently (Brewster et al., 1993; Haro et al., 1993; Mendoza et al., 1994). The salt-sensitive yeast mutants have been indispensable, for example, in the dissection of osmotic signaling pathways (Brewster et al., 1993; Maeda et al., 1994, 1995).

\section{Potassium Acquisition-A Critical Process for Salt Tolerance}

We have shown that sos1 mutants are hypersensitive to $\mathrm{Na}^{+}$ stress and defective in high-affinity $\mathrm{K}^{+}$uptake. These two phenotypes always cosegregated with each other (data not shown). In addition to sos1-1, the other three alleles also appear deficient in high-affinity $\mathrm{K}^{+}$uptake because they were not able to grow on low $\mathrm{K}^{+}$media (data not shown). Therefore, we conclude that the high-affinity $\mathrm{K}^{+}$uptake system is required

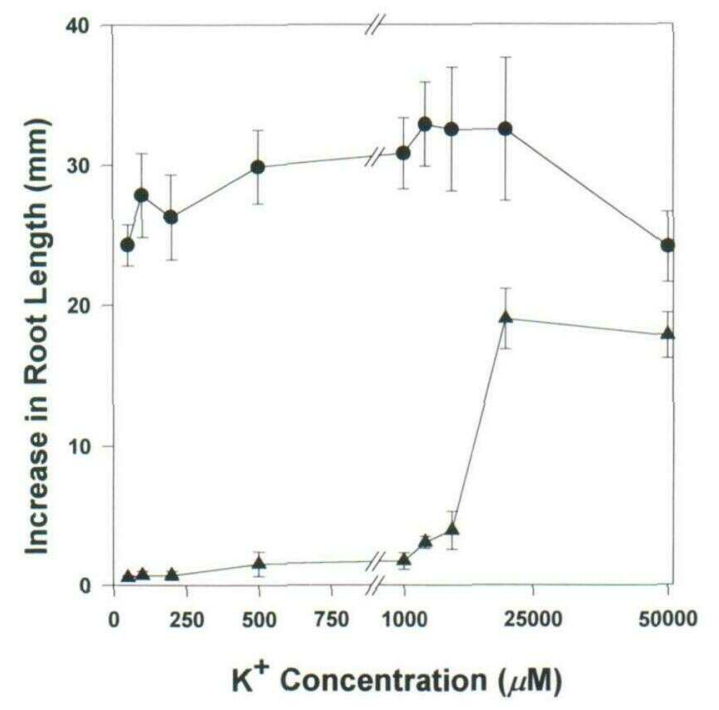

Figure 8. Growth of sos1 and Wild-Type Seedlings as a Function of Medium Potassium Concentration.

Root elongation was measured 1 week after transferring the seedlings from MS medium to media containing various levels of $\mathrm{K}^{+}$. Only at $\mathrm{K}^{+}$concentrations $>1 \mathrm{mM}$ was substantial growth of sos 1 plants observed. 

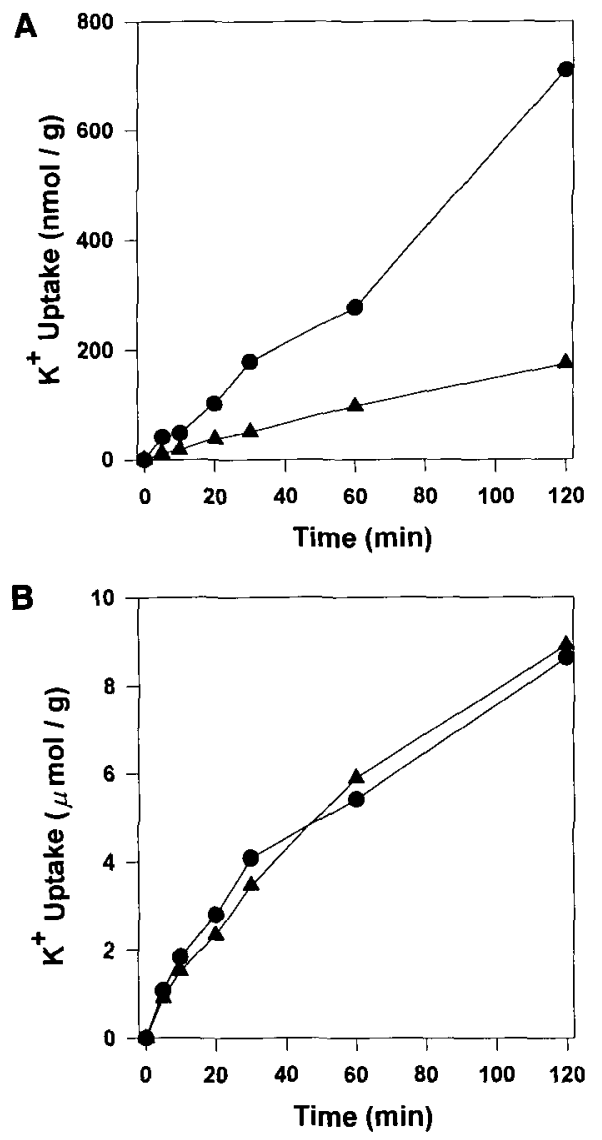

Figure 9. Potassium ( $\left.{ }^{86} \mathrm{Rb}\right)$ Uptake in sos1 and Wild-Type Seedlings as a Function of Time.

(A) Uptake at $200 \mu \mathrm{M}$ external $\mathrm{K}^{+}$.

(B) Uptake at $20 \mathrm{mM}$ external $\mathrm{K}^{+}$.

As shown in (A), sos1 is defective in high-affinity $\mathrm{K}^{+}$uptake. As shown in (B), low-affinity $\mathrm{K}^{+}$uptake is normal in sos1. - , wild type; $\mathbf{\Lambda}$, sos1.

for salt tolerance. A direct consequence of a defective highaffinity $\mathrm{K}^{+}$uptake system is $\mathrm{K}^{+}$deficiency, which was evident in NaCl-stressed sos1 plants (Figure 11). The difference in $\mathrm{K}^{+}$ uptake under $\mathrm{NaCl}$ stress is probably even greater, considering that the wild type was actively growing and thus diluting the cellular pool of $\mathrm{K}^{+}$. Potassium deficiency may in turn lead to increased cellular susceptibility to and damage by $\mathrm{NaCl}$. This is suggested by the observation that NaCl-treated sos1 seeds would not germinate even after being rescued to media without $\mathrm{NaCl}$. Furthermore, $\mathrm{K}^{+}$deficiency alone could not prevent the germination of sos1 or the wild-type seeds (data not shown). Our conclusion that high-affinity $\mathrm{K}^{+}$uptake is essential for salt tolerance also is supported by the observation that the yeast high-affinity $\mathrm{K}^{+}$transport mutant $t r k 1^{-}$is $\mathrm{NaCl}$ sensitive (Haro et al., 1993).

The hypothesis of dual mechanisms of potassium uptake was formulated more than three decades ago (Epstein et al.,
1963). Despite some reports of inconsistencies of experimental data with the hypothesis, it is supported by the majority of evidence in the literature. Recent studies indicate that the low-affinity uptake system is a $\mathrm{K}^{+}$channel(s), whereas the high-affinity system consists of a $\mathrm{K}^{+}-\mathrm{Na}^{+}$symporter(s) (Schroeder et al., 1994; Rubio et al., 1995). Thermodynamic principles dictate that the low-affinity system can only function in the transport of $\mathrm{K}^{+}$down its electrochemical potential gradient. The high-affinity system, with the tight coupling of proton motive force, can function in transporting $\mathrm{K}^{+}$against its electrochemical potential gradient. Compared with the lowaffinity system, the high-affinity system is slower and may be more costly in terms of cellular energy. However, this costly system is essential for plant survival when the external $\mathrm{K}^{+}$
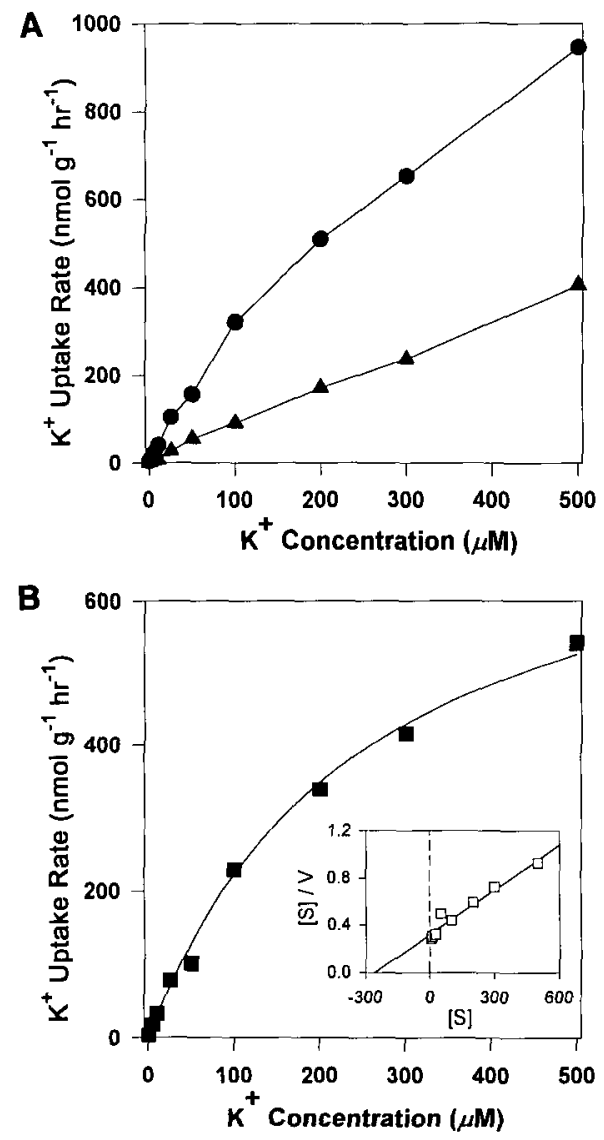

Figure 10. High-Affinity Potassium $\left({ }^{86} \mathrm{Rb}\right)$ Uptake in sos1 and WildType Seedlings.

(A) Uptake as a function of external $\mathrm{K}^{+}$concentration. , wild type; $\Delta$, sos1.

(B) SOS1-dependent high-affinity potassium uptake as a function of external $\mathrm{K}^{+}$concentration. The SOS1-dependent $\mathrm{K}^{+}$uptake was obtained by subtracting the uptake in sos 1 plants from that in the wild-type seedlings used for results in (A). The insert shows the Hanes plot of SOS7-dependent $\mathrm{K}^{+}$uptake. [S], $\mathrm{K}^{+}$concentration (micromolar); $\mathrm{V}, \mathrm{K}^{+}$ uptake rate (nanomoles per gram per hour). 


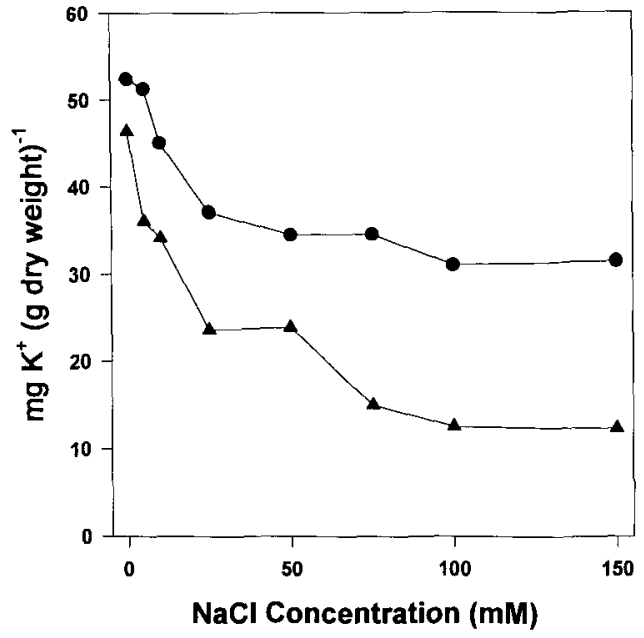

Figure 11. Potassium Content in sos1 and Wild-Jype Seedlings as a Function of $\mathrm{NaCl}$ Concentration in the External Media.

The media contain $\sim 10 \mathrm{mM} \mathrm{K}^{+}$(see Methods for details). $\mathrm{NaCl}$-treated sos1 plants show potassium deficiency. $\bullet$, wild type; $\boldsymbol{\Lambda}$, sos1.

concentration is low (Figures 7 and 8 ). It also is essential when plants are faced with high external $\mathrm{Na}^{+}$(Figure 1) even in the presence of $20 \mathrm{mM} \mathrm{K}^{+}$in the media. The addition of more $\mathrm{K}^{+}$ (up to $100 \mathrm{mM}$ ) to the $\mathrm{NaCl}$-containing media did not improve the growth of either sos1 or the wild type (L. Ding and J.-K. Zhu, unpublished data). The low-affinity system must not be functioning under such a condition of high external $\mathrm{Na}^{+}$. It is not known whether this is because it is thermodynamically unfavorable for the low-affinity system or because the plants actively turn off this system in response to $\mathrm{Na}^{+}$stress. An accurate thermodynamic calculation would require simultaneous measurement of membrane potential and cytoplasmic $\mathrm{K}^{+}$concentration. A switch from low-affinity to high-affinity $\mathrm{K}^{+}$uptake has been suggested to occur in yeast cells in response to $\mathrm{Na}^{+}$ stress (Haro et al., 1993). In any case, high $\mathrm{Na}^{+}$has been shown to inhibit low-affinity $\mathrm{K}^{+}$uptake, whereas high-affinity uptake is relatively unaffected (Epstein et al., 1963).

$\mathrm{K}^{+}$uptake is not only an integral part of salt tolerance mechanisms in glycophytes, but it may hold a key to improving salt tolerance. It appears that increased salt tolerance in saltadapted tobacco cells is accompanied by an enhanced $\mathrm{K}^{+}$uptake capacity (Watad et al., 1991). Increased $\mathrm{K}^{+} / \mathrm{Na}^{+}$selectivity of the high-affinity transporter $H K T 1$ from wheat has been shown to improve salt tolerance of transfected trk yeast cells (Rubio et al., 1995). The Knat locus, which controls $\mathrm{K}^{+} / \mathrm{Na}^{+}$ selectivity in wheat, appears to be important in plant productivity under an excess of soil $\mathrm{Na}^{+}$(Dvorak and Gorham, 1992). In addition, the yeast HAL1 gene, when overexpressed, confers osmotic and salt tolerance and enhances accumulation of $\mathrm{K}^{+}$in the presence of $\mathrm{NaCl}$ (Gaxiola et al., 1992).

It is tempting to speculate on the molecular nature of SOS1. One possibility is that $S O S 1$ encodes a high-affinity $\mathrm{K}^{+}$trans- porter similar to the cloned wheat gene HKT1. Alternatively, SOS1 could encode a regulator of the high-affinity transporter. Although $H K T 1$ alone was sufficient to provide the injected Xenopus oocytes with $\mathrm{K}^{+}$flux (Schachtman and Schroeder, 1994), there may be another component(s) required for its proper function in plants.

\section{METHODS}

\section{Plant Materials and Growth Conditions}

Arabidopsis thaliana (ecotype Columbia) carrying the homozygous recessive glabrous (g/1) mutation (Koornneef et al., 1982) was the parental strain of ethylmethane sulfonate (EMS)-mutagenized seed. The wild-type Arabidopsis Landsberg erecta ecotype used for genetic mapping was from the Arabidopsis stock center (Columbus, $\mathrm{OH}$ )

Seeds were surface sterilized by soaking in a solution of Clorox plus $0.01 \%$ Triton $X-100$ for $10 \mathrm{~min}$ and rinsing five times with sterile water. The seeds were resuspended in sterile $0.3 \%(w / v)$ low-melting-point agarose before being sown in rows onto agar plates for germination. The agar medium contained Murashige and Skoog (MS) salts (Murashige and Skoog, 1962) with $3 \%(w / v)$ sucrose and $1.2 \%(w / v)$ agar, $\mathrm{pH}$ 5.7. The plates were then stored at $4^{\circ} \mathrm{C}$ for $48 \mathrm{hr}$ to improve germination uniformity before being placed in a vertical position in a growth room for germination. When appropriate, seedlings (10 to 20 days old) were transferred to soil (Pro-Mix XB; Premier Brands Inc., Red Hill, PA) and grown to maturity. Plotted plants were watered twice a week, once with a nutrient solution (Peter's 15-16-17; Grace-Sierra Horticultural Products, Milpitas, CA). Temperature in the growth room was $23 \pm 2^{\circ} \mathrm{C}$. Light provided by cool-white fluorescent bulbs was 50 to $70 \mu \mathrm{E} \mathrm{m}^{-2} \mathrm{sec}^{-1}$ (constant) for seedlings in agar plates and $\sim 100$ $\mu \mathrm{E} \mathrm{m}^{-2} \mathrm{sec}^{-1}$ (16-hr light/8-hr dark) for potted plants.

\section{Isolation of Mutants and Genetic Analysis}

EMS-mutagenized $\mathrm{M}_{2}$ seed were obtained from Lehle Seeds (Round Rock, TX). Approximately $50,000 \mathrm{M}_{2}$ seeds representing $\sim 6500 \mathrm{M}_{1}$ lines were screened for $\mathrm{NaCl}$-hypersensitive mutants by using a rootbending assay. Four-day-old seedlings with 1- to $1.5-\mathrm{cm}$-long roots were transferred from the vertical agar plates, one by one, onto a second agar medium that was supplemented with $50 \mathrm{mM} \mathrm{NaCl}$. The seedlings were arranged in rows, and the plates were oriented vertically

Table 2. Genetic Mapping of sos1

\begin{tabular}{llll}
\hline Markers & Chromosome & $n^{\mathrm{a}}$ & $\begin{array}{l}\text { Recombination Frequency } \\
(\% \pm \mathrm{SE})\end{array}$ \\
\hline nga63 & I & 28 & $44.6 \pm 6.6$ \\
nga168 & II & 43 & $37.2 \pm 5.2$ \\
GPA1 & II & 43 & $24.4 \pm 4.6$ \\
nga8 & IV & 33 & $45.5 \pm 6.1$ \\
nga76 & V & 28 & $50.0 \pm 6.7$ \\
\hline
\end{tabular}

a Number of samples analyzed.

b Calculated by the Kosambi function (Koorneef and Stam, 1992). 
with the roots pointing upward. Root growth and subsequent downward curving were apparent several hours after the transfer. Roots that did not show curving and apparent growth were noted, and the putative mutant seedlings were picked up 3 to 7 days later and placed on a $0.6 \%$ agar medium (without $\mathrm{NaCl}$ ) to grow to six to seven rosette leaves. Twenty-one putative mutants were then transferred to soil to grow to maturity.

Aliquots of seeds from the putative mutants were screened again, using the above root-bending assay on agar plates with $50 \mathrm{mM} \mathrm{NaCl}$ or no $\mathrm{NaCl}$ (Figure 1B). Of the 21 putative mutants, four exhibited normal root bending on agar plates without $\mathrm{NaCl}$, but no root bending was exhibited on plates with $50 \mathrm{mM} \mathrm{NaCl}$; thus, the mutants were considered true salt-hypersensitive.

Mutants were crossed with the wild type (Columbia, g/7) by rubbing stamens from the mutants onto the stigma of emasculated wild-type flowers. The mutants also were crossed with each other for allelic tests. The $\mathrm{NaCl}$ sensitivity of $\mathrm{F}_{1}$ and $\mathrm{F}_{2}$ seedlings arising from the crosses was determined by the root-bending assay on $75 \mathrm{mM} \mathrm{NaCl}$ plates.

\section{Growth Measurement}

For stress treatments and growth measurement, 4-day-old seedlings from vertical plates were transferred and placed with roots pointing downward onto vertical agar plates supplemented with various salts. Each plate contained five mutant and five wild-type seedlings. Three replicate plates were used for each treatment. Increases in root length were measured with a ruler every day for 7 days.

Potassium-free medium was prepared by replacing $\mathrm{MS}$ salts with the following: $1650 \mathrm{mg} / \mathrm{L} \mathrm{NH}_{4} \mathrm{NO}_{3}, 440 \mathrm{mg} / \mathrm{L} \mathrm{CaCl} 2 \cdot 2 \mathrm{H}_{2} \mathrm{O}, 370 \mathrm{mg} / \mathrm{L}$ $\mathrm{MgSO}_{4} \cdot 7 \mathrm{H}_{2} \mathrm{O}, 165 \mathrm{mg} / \mathrm{L}\left(\mathrm{NH}_{4}\right)_{2} \mathrm{HPO}_{4}, 27.8 \mathrm{mg} / \mathrm{L} \mathrm{FeSO}{ }_{4} \cdot 7 \mathrm{H}_{2} \mathrm{O}, 37.3$ $\mathrm{mg} / \mathrm{L}$ disodium EDTA, $0.7495 \mathrm{mg} / \mathrm{L} \mathrm{Nal}, 6.3 \mathrm{mg} / \mathrm{L} \mathrm{H}_{3} \mathrm{BO}_{3}, 16.9 \mathrm{mg} / \mathrm{L}$ $\mathrm{MnSO}_{4} \cdot \mathrm{H}_{2} \mathrm{O}, 8.6 \mathrm{mg} / \mathrm{L} \mathrm{ZnSO}{ }_{4} \cdot 7 \mathrm{H}_{2} \mathrm{O}, 0.25 \mathrm{mg} / \mathrm{L} \mathrm{Na} \mathrm{MO}_{4} \cdot 2 \mathrm{H}_{2} \mathrm{O}, 0.016$ $\mathrm{mg} / \mathrm{L} \mathrm{CuSO}{ }_{4} \cdot 5 \mathrm{H}_{2} \mathrm{O}$, and $0.0267 \mathrm{mg} / \mathrm{L} \mathrm{CoSO}_{4} \cdot 6 \mathrm{H}_{2} \mathrm{O}$. Where stated, $\mathrm{NH}_{4} \mathrm{NO}_{3}$ was replaced with an equal molar concentration of Trisnitrate (Sigma) to determine any toxic effect of $\mathrm{NH}_{4}{ }^{+}$on Arabidopsis root growth (Cao et al., 1993). Varying levels of potassium in the media were achieved by adding appropriate amounts of $\mathrm{KCl}$ to the $\mathrm{K}^{+}$-free medium.

\section{Determination of $\mathrm{K}^{+}$Content}

Approximately 150 seeds were sterilized and incubated in a $250-\mathrm{mL}$ flask containing $75 \mathrm{~mL}$ of medium (half-strength MS salts and $2 \%$ sucrose, $\mathrm{pH}$ 5.5). The flasks were shaken at $120 \mathrm{rpm}$ in a chamber with continuous cool fluorescent light illumination and $22^{\circ} \mathrm{C}$ temperature. After 8 days, the appropriate amount of $5 \mathrm{M} \mathrm{NaCl}$ was added to give a desired $\mathrm{NaCl}$ concentration, and the seedlings were allowed to continue to grow for specified time periods. The seedlings were collected, rinsed five times briefly with distilled water (total of $100 \mathrm{~mL}$ of water), weighed, and dried at $65^{\circ} \mathrm{C}$ for $24 \mathrm{hr}$. After dry weight measurement, $\mathrm{K}^{+}$content was determined by atomic absorption spectrophometry.

\section{Measurement of Potassium ( $\left.{ }^{86} \mathrm{Rb}\right)$ Uptake}

For measurement of potassium uptake, using ${ }^{86} \mathrm{Rb}$ as a tracer, 4-dayold seedlings from vertical $M S$ agar plates were transferred to vertical agar plates containing $5 \mu \mathrm{M} \mathrm{K}^{+}$. After 2.5 days, 13 seedlings were collected, rinsed briefly in $\mathrm{K}^{+}$-free medium, and then added to a $10-\mathrm{mL}$ uptake solution containing $\mathrm{K}^{+}$-free medium supplemented with appropriate amounts of $\mathrm{KCl}$ and $0.5 \mu \mathrm{Ci} / \mathrm{mL}$ of ${ }^{86} \mathrm{Rb}$ (Amersham). The uptake was performed at $23^{\circ} \mathrm{C}$ under white fluorescent light. Uptake at different $\mathrm{K}^{+}$concentrations was performed for $30 \mathrm{~min}$. Uptake at $200 \mu \mathrm{M}$ or $20 \mathrm{mM} \mathrm{K}^{+}$was performed for $5,10,20,30,60$, and $120 \mathrm{~min}$. At the completion of uptake, the seedlings were rinsed twice ( $15 \mathrm{sec}$ each) in $30 \mathrm{~mL}$ of $\mathrm{K}^{+}$-free media and incubated for $15 \mathrm{~min}$ in $35 \mathrm{~mL}$ of icecold $\mathrm{K}^{+}$-free media. In the case of uptake at $20 \mathrm{mM} \mathrm{K}^{+}$, rinsing solutions were supplemented with $40 \mathrm{mM}$ mannitol for osmotic balance. The seedlings were blotted dry on filter paper and weighed, and the radioactivity was measured in a scintillation counter.

\section{Callus Initiation and Maintenance}

Calli were generated from the wild type and mutants by sowing seeds directly on a medium containing the following: MS salts, $2 \%$ sucrose, $10 \mathrm{mg} / \mathrm{L}$ myo-inositol, $100 \mu \mathrm{g} / \mathrm{L}$ nicotinic acid, $1 \mathrm{mg} / \mathrm{L}$ thiamine- $\mathrm{HCl}$, $100 \mu \mathrm{g} / \mathrm{L}$ pyridoxin- $\mathrm{HCl}, 400 \mu \mathrm{g} / \mathrm{L}$ glycine, $0.23 \mu \mathrm{M}$ kinetin, $4.5 \mu \mathrm{M} 2,4-\mathrm{D}$, and $1 \%(\mathrm{w} / \mathrm{v})$ agar, $\mathrm{pH}$ 5.7. After 2 weeks, the calli were transferred to a callus maintenance medium with the above-mentioned components, except that the kinetin and 2,4-D concentrations were changed to 0.46 and $2.25 \mu \mathrm{M}$, respectively.

\section{ACKNOWLEDGMENTS}

We thank Drs. Paul M. Hasegawa, Robert Locy, Ray Bressan, and Joe Shaw for helpful discussions. We also thank Dr. Leon Kochian for advice on potassium uptake experiments. The work was supported by the Alabama Agricultural Experiment Station and a grant from the U.S. Department of Agriculture National Research Initiative Competitive Grants Program (Plant Responses to the Environment) to J.-K.Z.

Received November 30, 1995; accepted February 12, 1996.

\section{REFERENCES}

Anderson, J.A., Huprikar, S.S., Kochian, L.V., Lucas, W.J., and Gaber, R.F. (1992). Functional expression of a probable Arabidopsis thaliana potassium channel in Saccharomyces cerevisiae. Proc. Natl. Acad. Sci. USA 89, 3736-3740.

Bell, C.J., and Ecker, J.R. (1994). Assignment of 30 microsatellite loci to the linkage map of Arabidopsis. Genomics 19, 137-144.

Binzel, M.L., and Reuveni, M. (1994). Cellular mechanisms of salt tolerance in plant cells. Hortic. Rev. 16, 33-69.

Bray, E.A. (1993). Molecular responses to water deficit. Plant Physiol. 103, 1035-1040.

Brewster, J.L., de Valoir, T., Dwyer, N.D., Winter, E., and Gustin, M. (1993). An osmosensing signal transduction pathway in yeast. Science 259, 1760-1763.

Cao, Y., Glass, A.M. , and Crawford, N.M. (1993). Ammonium inhibition of Arabidopsis root growth can be reversed by potassium and by auxin resistance mutations aux1, axr1, and axr2. Plant Physiol. 102, 983-989. 
Cushman, J.C., DeRocher, E.J., and Bohnert, H.J. (1990). Gene expression during adaptation to salt stress. In Environmental Injury to Plants, F.J. Katerman, ed (New York: Academic Press), pp. 173-203.

Dvorak, J., and Gorham, J. (1992). Methodology of gene transfer by homologous recombination into Triticum tugidum: Transfer of $\mathrm{K}+/ \mathrm{Na}^{+}$discrimination from $\mathrm{T}$. aestivum. Genome 35, 639-646.

Epstein, E. (1966). Dual pattern of ion absorption by plant cells and by plants. Nature 212, 1324-1327.

Epstein, E. (1972). Mineral Nutrition in Plants: Principles and Perspectives. (New York: John Wiley and Sons).

Epstein, E., Rains, D.W., and Elzam, O.E. (1963). Resolution of dual mechanisms of potassium absorption by barley roots. Proc. Natl. Acad. Sci. USA 49, 684-692.

Epstein, E., Norlyn, J.D., Rush, D.W., Kingsbury, R.W., Kelly, D.B., Cunningham, G.A., and Wrona, A.F. (1980). Saline culture of crops: A genetic approach. Science 210, 399-404.

Gaxiola, R., de Larrinoa, I.F., Villalba, J.M., and Serrano, R. (1992). A novel and conserved salt-induced protein is an important determinant of salt tolerance in yeast. EMBO J. 11, 3157-3164.

Greenway, H., and Munns, R. (1980). Mechanisms of salt tolerance in nonhalophytes. Annu. Rev. Plant Physiol. 31, 149-190.

Hadjeb, N., and Berkowitz, G.A. (1995). Cloning of a third plant $K^{+}$ channel cDNA. Plant Physiol. 108, 38.

Haro, R., Baneulos, M.A., Quintero, F.J., Rubio, F., and RodriguezNavarro, A. (1993). Genetic basis of sodium exclusion and sodium tolerance in yeast. A model for plants. Physiol. Plant. 89, 868-874.

Howden, R., and Cobbett, C.S. (1992). Cadmium-sensitive mutants of Arabidopsis thaliana. Plant Physiol. 99, 100-107.

Ko, C.H., and Gaber, R.F. (1991). TRK1 and TRK2 encode structurally related $\mathrm{K}^{+}$transporters in Saccharomyces cerevisiae. Mol. Cell. Biol. 11, 4266-4273.

Kochian, L.V., and Lucas, W.J. (1988). Potassium transport in roots. Adv. Bot. Res. 15, 93-178.

Konieczny, A., and Ausubel, F. (1993). A procedure for quick mapping of Arabidopsis mutants using ecotype specific markers. Plant J. 4, 403-410.

Koornneef, M., and Stam, P. (1992). Genetic analysis. In Methods in Arabidopsis Research, C. Koncz, N.-H. Chua, and J. Schell, eds (Singapore: World Scientific), pp. 83-99.

Koornneef, M., Dellaert, L.W.M., and van der Veen, J.H. (1982). EMSand radiation-induced mutation frequencies at individual loci in Arabidopsis thaliana (L.) Heynh. Mutat. Res. 93, 109-123.

Maathuis, F.J., and Sanders, D. (1994). Mechanism of high-affinity potassium uptake in roots of Arabidopsis thaliana. Proc. Natl. Acad. Sci. USA 91, 9272-9276.

Maeda, T., Wurgler-Murphy, S.M., and Saito, H. (1994). A twocomponent system that regulates an osmosensing MAP kinase cascade in yeast. Nature $369,242-245$.
Maeda, T., Takekawa, M., and Saito, H. (1995). Activation of yeast PBS2 MAPKK by MAPKKKs or by binding of an SH3-containing osmosensor. Science 269, 554-558.

Mendoza, I., Rubio, F., Rodriguez-Navarro, A., and Pardo, J.M. (1994). The protein phosphatase calcineurin is essential for $\mathrm{NaCl}$ tolerance of Saccharomyces cerevisiae. J. Biol. Chem. 269, 8792-8796.

Meyerowitz, E.M., and Somerville, C.R. (1994). Arabidopsis. (Cold Spring Harbor, NY: Cold Spring Harbor Laboratory).

Murashige, T., and Skoog, F. (1962). A revised medium for rapid growth and bioassays with tobacco tissue culture. Physiol. Plant. 15, 473-497.

Murphy, A., and Taiz, L. (1995). A new vertical mesh transfer technique for metal-tolerance studies in Arabidopsis. Plant Physiol. 108, 29-38.

Polley, D.L., and Hopkins, J.W. (1979). Rubidium (potassium) uptake by Arabidopsis. Plant Physiol. 64, 374-378.

Rains, D.W., and Epstein, E. (1967). Sodium absorption by barley roots: Its mediation by mechanism 2 of alkali cation transport. Plant Physiol. 42, 319-323.

Rubio, F., Gassmann, W., and Schroeder, J.I. (1995). Sodium-driven potassium uptake by the plant potassium transporter HKT1 and mutations conferring salt tolerance. Science 270, 1660-1663.

Saleki, R., Young, P.G., and Lefebvre, D.D. (1993). Mutants of Arabidopsis thaliana capable of germination under saline conditions. Plant Physiol. 101, 839-845.

Schachtman, D.P., and Schroeder, J.I. (1994). Structure and transport mechanism of a high affinity potassium uptake transporter from higher plants. Nature 370, 655-658.

Schachtman, D.P., Schroeder, J.I., Lucas, W.J., Anderson, J.A., and Gaber, R.F. (1992). Expression of an inward-rectifying potassium channel by the Arabidopsis KAT1 cDNA. Science 258, 1654-1658.

Schroeder, J.I., Ward, J.M., and Gassmann, W. (1994). Perspectives on the physiology and structure of inward-rectifying $\mathrm{K}^{+}$channels in higher plants: Biophysical implications for $\mathrm{K}^{+}$uptake. Annu. Rev. Biophys. Biomol. Struct. 23, 441-471.

Sentenac, H., Bonneaud, N., Minet, M., Lacroute, F., Salmon, J.-M., Gaymard, F., and Grignon, C. (1992). Cloning and expression in yeast of a plant potassium ion transport system. Science 256, 663-665.

Serrano, R., and Gaxiola, R. (1994). Microbial models and salt stress tolerance in plants. Crit. Rev. Plant Sci. 13, 121-138.

Sheahan, J.J., Ribeiro-Neto, L., and Sussman, M.R. (1993). Cesiuminsensitive mutants of Arabidopsis thaliana. Plant J. 3, 647-656.

Watad, A.-E.A., Reuveni, M., Bressan, R.A., and Hasegawa, P.M. (1991). Enhanced net $\mathrm{K}^{+}$uptake capacity of $\mathrm{NaCl}$-adapted cells. Plant Physiol. 95, 1265-1269.

Werner, J.E., and Finkelstein, R.R. (1995). Arabidopsis mutants with reduced response to $\mathrm{NaCl}$ and osmotic stress. Physiol. Plant. 93, 659-666. 
SOS1, a Genetic Locus Essential for Salt Tolerance and Potassium Acquisition

S. J. Wu, L. Ding and J. K. Zhu

PLANT CELL 1996;8;617-627

DOI: $10.1105 /$ tpc.8.4.617

This information is current as of January 13, 2009

Permissions

eTOCs

CiteTrack Alerts

Subscription Information
https://www.copyright.com/ccc/openurl.do?sid=pd_hw1532298X\&issn=1532298X\&WT.mc_id=pd_hw153229 $8 \mathrm{X}$

Sign up for eTOCs for THE PLANT CELL at:

http://www.plantcell.org/subscriptions/etoc.shtml

Sign up for CiteTrack Alerts for Plant Cell at:

http://www.plantcell.org/cgi/alerts/ctmain

Subscription information for The Plant Cell and Plant Physiology is available at: http://www.aspb.org/publications/subscriptions.cfm 